\title{
O DEVER DE CASA E SUA RELAÇÃO COM A ZONA DE DESENVOLVIMENTO PROXIMAL
}

\author{
LOS DEBERES Y SU RELACIÓN CON EL AREA DE DESARROLLO PROXIMAL
}

HOMEWORK AND ITS RELATIONSHIP WITH THE PROXIMAL DEVELOPMENT AREA

\author{
Alisson da SILVA SOUZA ${ }^{1}$
}

RESUMO: O presente texto propõe uma reflexão sobre um instrumento didático muito utilizado nas escolas para complementar os conteúdos trabalhados em classe, o dever de casa. Partindo do conceito científico de Zona de Desenvolvimento Proximal (ZPD), desenvolvido pelo psicólogo russo Lev Vigotski (2007), buscamos compreender o sentido e o significado dessa política, tanto para a escola quanto para a família. Trata-se de um estudo qualitativo recorrendo-se uma revisão bibliográfica. Esta aponta que este instrumento de/para aprendizagem é um elo entre a família e a escola, (CARVALHO, 2004; 2006; CARNEIRO 2010; OLIVEIRA; MARINHO ARAÚJO, 2010; RESENDE, 2006; 2012; 2018), no entanto, revela também que os territórios escolares ainda necessitam refletir, estudar e discutir essa política-prática e seus modos de uso.

PALAVRAS-ChAVE: Educação. Dever de casa. Zona de desenvolvimento proximal. Família-escola.

RESUMEN: Este texto propone una reflexión sobre un instrumento didáctico muy utilizado en las escuelas para complementar los contenidos trabajados en clase, los deberes. Partiendo del concepto científico de Zona de Desarrollo Proximal (ZPD), desarrollado por el psicólogo ruso Lev Vigotski (2007), buscamos comprender el significado y trascendencia de esta política, tanto para la escuela como para la familia. La revisión de la literatura señala que esta herramienta es un vínculo entre la familia y la escuela, (CARVALHO, 2004; 2006; CARNEIRO 2010; OLIVEIRA; MARINHO ARAÚJO, 2010; RESENDE 2006; 2012; 2018), sin embargo, también revela que los territorios escolares Todavía es necesario reflexionar, estudiar y discutir esta política-práctica y sus modos de uso.

PALABRAS CLAVE: Educación. Deberes de la casa. Zona de desarrollo próximo. Escuelafamilia.

ABSTRACT: This text proposes a reflection on a didactic instrument widely used in schools to complement the contents worked in class, homework. Starting from the scientific concept of the Proximal Development Zone (PDZ), developed by the Russian psychologist Lev Vigotski (2007), we seek to understand the meaning and significance of this policy, both for the school

1 Secretaria Municipal de Educação de Santo Antônio de Jesus, Santo Antônio de Jesus - BA - Brasil. Coordenador pedagógico da Creche Criança Feliz I. Psicólogo (UFRB). Mestrado em Educação (UEFS). ORCID: https://orcid.org/0000-0001-6239-1367. E-mail: pot_ppb@hotmail.com. 
and for the family. The bibliographic review points out that this tool is a link between family and school, (CARVALHO, 2004; 2006; CARNEIRO 2010; OLIVEIRA; MARINHO ARAÚJO, 2010; RESENDE 2006; 2012; 2018), however, also reveals that school territories still need to reflect, study and discuss this policy-practice and its modes of use.

KEYWORDS: Education. Homework. Zone of proximal development. Family-school.

\section{Introdução}

Mediante uma provocação teórica sobre o dever de casa como uma política-prática, realizada por Carvalho (2004), este artigo busca compreender o sentido e o significado dos seus usos na relação entre a família e a escola. O presente estudo se une a uma produção já existente sobre o assunto, realizada por Carvalho (2004; 2005; 2006), Carneiro (2010), Oliveira, Marinho Araújo (2010) e Resende (2006; 2012; 2018), dentre outros, contudo, apresenta contribuições para a compreensão da importância do tema a partir do conceito de Zona de Desenvolvimento Proximal desenvolvido na obra de Lev Vigotski.

O caminho metodológico foi construído a partir da análise de trabalhos publicados na Biblioteca Digital de Teses e dissertação - BDTD e SciELO, The Scientific Electronic Library Online. Na busca realizada para os artigos, teses e dissertações, a categoria de análise (palavras-chave) utilizada foi: dever de casa. É importante assinalar que o presente texto não se trata apenas de um trabalho de revisão de literatura, logo, não foi realizado um recorte cronológico das publicações, tendo em vista também que dispomos de um número bastante reduzido de pesquisas que tratam do assunto.

Assim, o presente texto discute, inicialmente, acerca das contribuições de estudiosos que se dedicam às pesquisas sobre o dever de casa, situando-as no campo das pesquisas educacionais e, em seguida, aponta elementos para a compreensão de sua importância pela via da Psicologia da Educação.

\section{Dever de casa, família e escola: apontamentos para uma reflexão}

Para Resende (2006), a prescrição de atividades escolares para serem realizadas em casa não é uma prática recente. Numa contextualização histórica, a autora situa que a partir das últimas duas décadas do século XX se observa um movimento mais intenso de imbricação entre família e escola em torno da realização de atividades extraclasse.

Carvalho (2006) pontua que tradicionalmente o dever de casa tem sido considerado uma estratégia de ensino do currículo escolar: um exercício de revisão, reforço, fixação, que 
serve para preparar o aluno para os conteúdos posteriores ou para uma eventual avaliação. A autora defende que é importante compreender o dever de casa como uma política-prática, pois compreende discursos-práticas formais e informais, explícitos e implícitos, envolvendo vários atores sociais, além das diretrizes governamentais (CARVALHO, 2004, p. 94).

No território brasileiro, o dever de casa funciona como uma política explícita, um instrumento de regulação das famílias em relação à escola, em parte, o objetivo desse controle se justifica em prol do aproveitamento escolar. Soares (2011), compreende o dever de casa como uma questão política e argumenta que a escola, por meio dessas atividades, estende às famílias dos estudantes os valores educacionais que preconiza.

Apesar das recorrentes críticas que têm sido realizadas, seja pelo seu excesso, ou pela sua repetição mecânica dos conteúdos que são trabalhados em classe, o dever de casa, ao longo do tempo, passou a ser visto como uma necessidade educacional reconhecida por pais e professores, ou seja, passou a ser o principal meio de interação entre família e escola.

Oliveira e Marinho-Araújo (2010, p. 101), explicitam as divergências entre essas duas agencias socializadoras:

A divergência entre escola e família está na tarefa de ensinar, sendo que a primeira tem a função de favorecer a aprendizagem dos conhecimentos construídos socialmente em determinado momento histórico, de ampliar as possibilidades de convivência social e, ainda, de legitimar uma ordem social, enquanto a segunda tem a tarefa de promover a socialização das crianças, incluindo o aprendizado de padrões comportamentais, atitudes e valores aceitos pela sociedade.

Marques (1999) salienta a existência da parceria entre família e escola e alega que uma das principais estratégias do dever de casa é o envolvimento dos pais em atividades de aprendizagem em casa, participação na realização de trabalhos, projetos e deveres de casa.

Numa crítica a essa perspectiva, Oliveira e Marinho-Araújo (2010) apontam que tais atitudes de envolvimento dos pais se reduzem à colaboração nas atividades e no desempenho dos seus filhos. Conforme as autoras, as expectativas quanto à participação dos pais envolvem o acompanhamento da tarefa de casa ou a formação do aluno em termos de disciplina, respeito e comportamento adequado.

Carvalho (2004) compreende que o dever de casa é parte integrante do processo de ensino-aprendizagem, contudo reconhece que sua implementação afeta a vida dos estudantes fora da escola e sua rotina familiar, pois supõe a conexão entre as atividades de sala de aula e de casa, e uma estrutura doméstica adequada apoiando as atividades escolares. Ao realizar uma análise sobre os trabalhos de Clark (1993), Eric (2000), Henderson e Berla (1994), 
Carvalho (2004) identifica uma clara preponderância de avaliações favoráveis à produtividade do dever de casa no aproveitamento escolar. Para a autora, as atividades concentram-se em “áreas como dificuldades de aprendizagem, programas de educação compensatória, motivações e valores das famílias e dos estudantes, e relevância conceitual da tarefa, no contexto do planejamento e avaliação do ensino" (CARVALHO, 2004, p. 96).

Para Franco (2002 apud RESENDE, 2008), o dever de casa é considerado como toda atividade pedagógica elaborada e proposta por professores, destinada ao trabalho dos alunos fora do período regular de aulas. Geralmente, as atividades que são enviadas para os estudantes fazerem em casa, é uma extensão daquilo que foi desenvolvido na classe. Muitas propostas pedagógicas acreditam que é por meio dessa prática de repetição que a aprendizagem se consolida. Concordando ou não, o fato é que em todas as escolas prevalece o "tradicional" dever de casa.

Entendido como parte integrante do processo de ensino-aprendizagem, o dever de casa também pode ser visto como uma maneira de manter o aluno ocupado em casa, porém seu excesso castra o tempo livre tão necessário ao exercício da criatividade e da autonomia da criança. Entretanto, não se pode desconsiderar que a atividade extraclasse, se bem programada e previamente planejada, pode interferir de maneira positiva na aprendizagem da classe.

Compreendido como uma política formativa que molda as relações família-escola, o dever de casa ainda carece de mais estudos no campo das pesquisas educacionais. Em sua pesquisa de mestrado, Soares (2011) realizou uma busca minuciosa nos sites da Biblioteca Digital de Teses e dissertação - BDTD e da Associação Nacional e Pós-Graduação e Pesquisa em Educação - ANPEd com o objetivo de compreender e evidenciar as pesquisas mais relevantes sobre o tema no período de 2000 a 2009. Os achados da autora revelam uma diminuta incidência de trabalhos relacionados ao tema, demonstrando assim um escasso investimento de pesquisas e publicações.

Partindo da perspectiva de que no campo das práticas escolares, o dever de casa é praticamente uma unanimidade. Carneiro (2010) assinala que as razões para sua prescrição se justificam pela valorização de um desenvolvimento cognitivo que possibilite um comportamento autônomo e autorregulado do aluno, assim como no discurso neoliberal que, atrelado à educação, valoriza as técnicas de organização e pensamento estratégico (CARNEIRO, 2010, p. 36).

Considerado um elo entre família e escola, Resende (2006) salienta que o uso excessivo do dever de casa se popularizou a partir das duas últimas décadas. Ao realizar uma análise macro da conjuntura política, Soares (2011) destaca que é nesse período que se 
intensifica o discurso neoliberal de escolas como motor de eficiência, estimulando a competitividade individual e institucional e que a partir desse momento a responsabilização das famílias pelo aproveitamento escolar se tornou mais evidente.

Resende e colaboradores (2018) buscaram compreender diferentes concepções e práticas em torno dos deveres de casa em escolas que desenvolvem projetos de ampliação da jornada escolar. Após pesquisa de campo realizada por meio de questionários, as pesquisadoras encontraram dados que indicam acirramento dos conflitos em torno dos deveres de casa e da divisão do trabalho educacional entre família e escola.

Em pesquisa recente, Suehiro e Boruchovitch (2019) pontuam que o progresso e o sucesso escolar estão associados à motivação para ler e o envolvimento do estudante na realização de diferentes tipos de tarefas.

Conforme Suehiro e Boruchovitch (2019, p. 1-2):

A lição ou tarefa de casa é uma atividade extraescolar que os escolares devem realizar em casa, com o objetivo de rever e estudar o que aprenderam durante as aulas. Pode envolver desde leituras, exercícios escritos, resolução de problemas e pesquisas, até outros fazeres de diferentes complexidades.

As autoras constataram também que o dever de casa pode se tornar algo complexo e desmotivador, tendo em vista que a leitura, um dos principais veículos de disseminação de informação, tem sido permeada por muitas dificuldades, especialmente no contexto brasileiro. Ainda nessa pesquisa, as autoras discutem a importância da motivação intrínseca e estendem que esta é qualitativamente a melhor forma de engajamento e a que propicia resultados de aprendizagem mais expressivos (SUEHIRO; BORUCHOVITCH, 2019, p. 2).

Para Suehiro e Boruchovitch (2019, p. 2):

Em geral, escolares com esse tipo de motivação apresentam melhor desempenho escolar e processamento mais profundo da informação; estratégias de aprendizagem mais eficazes e sofisticadas; bem-estar psicológico; autopercepção adequada da competência; e baixos níveis de ansiedade.

Críticas à parte, o dever de casa é um importante recurso quando se trata do aproveitamento escolar, pois ao levar para o ambiente da família o que é trabalhado na escola, a criança tem a possibilidade de ressignificar ou reelaborar o que não ficou muito claro no momento da aula e isso pode acontecer por meio ou a partir da mediação de um outro mais instrumentalizado. Contudo, o que as pesquisas têm revelado é que prevalece um modelo de motivação extrínseca pautado por recompensa e desempenho acadêmico, motivos externos ao estudante, principalmente quando se trata de crianças. 
Quando se trata de crianças, a colaboração dos pais no processo de aprendizagem tem um valor central, pois seus papéis sociais legitimam a conexão entre o que é aprendido na escola com o mundo da vida cotidiana, reafirmando os laços de afetividade e responsabilidade tão necessários ao desenvolvimento pleno do ser humano.

No entanto, mesmo sabendo da responsabilidade que lhes é implícita, muitos pais terceirizam às bancas e reforços escolares a função de acompanhar o desenvolvimento e o rendimento escolar de seus filhos. Há casos também de pais que, por falta de tempo ou de paciência, acabam realizando a tarefa pelos filhos, o que prejudica a aprendizagem e reforça no pensamento da criança, a ideia do dever de casa como um fardo ou algo que os pais buscam encontrar modos de livrar os filhos. As ações são empreendidas, de modo geral, em decorrência de pressões, obrigações, prazos fatais, recompensas, punições e ameaças, entre outros motivos (SUEHIRO; BORUCHOVITCH, 2019, p. 2).

Ao estudar as visões e as experiências de mães e mães professoras em relação aos deveres de casa, Carvalho e Burity (2005) destacam que estas confirmam o discurso da escola de valorização dos deveres de casa, contudo, sua realização no contexto da família revela contradições. A análise do conteúdo das entrevistas contrasta com o que dizem as entrevistadas: "é nas camadas mais pobres da população, cujas crianças estudam na escola pública, que esses embates se evidenciam mais fortemente, sugerindo que o dever de casa pode estar apresentando efeito contrário aos benefícios dele esperado" (SOARES, 2011, p. 43).

\section{O dever de casa e a Zona de Desenvolvimento Proximal}

Neste texto, com base em Vigostski (2007), defendo a importância das atividades de casa como uma forma de antecipação do que acontece no contexto da escola. Ou seja, compreendo que tais atividades devem ser planejadas no sentido de promover o desenvolvimento dos estudantes, tendo em vista o que eles já sabem, Zona de Desenvolvimento Real (ZDR), e o que podem vir a aprender sozinhos ou com a ajuda de outro parceiro mais experiente, Zona de Desenvolvimento Proximal (ZDP).

No contexto da escola, crianças e professores por meio de suas interações podem ativar Zonas de Desenvolvimento Proximal em situações de ensino-aprendizagem e por meio de resolução de atividades e tarefas. A qualidade das interações estabelecidas na escola, entre professor-aluno e aluno-aluno, podem favorecer as aprendizagens, pois é por meio dessas interações que as Zonas de Desenvolvimento Proximal são desencadeadas, o que permite ao 
professor compreender melhor o processo de ensino e ritmo de desenvolvimento de sua turma.

De acordo com Fino (2001), o desenvolvimento consiste num processo de aprendizagem que acontece por meio das interações sociais com os outros mais experimentados. Nesse sentido, podemos compreender que o conceito de Zona de Desenvolvimento Proximal, postulado por Vigotski (2007), se refere a esta experiência da criança com adultos ou com um parceiro mais experiente.

Um aspecto fundamental da obra de Vigotski relacionado à interação social é a mediação, conceito importante da teoria histórico-cultural. Para este autor nossas ações no mundo físico e social nunca se dão de forma direta e, sim, de forma mediada e indireta, por meio de símbolos e signos e de outros indivíduos.

De acordo com Rego (2014), no desenvolvimento da teoria histórico-cultural, preconizada por Vigotski, o papel do professor na mediação da aprendizagem dos alunos ocupa um lugar central, pois é este que permite ao aluno por meio de suas intervenções saltar de um nível de desenvolvimento para outro.

Sobre isso Vigotski, (2007, p. 98) acrescenta que:

A Zona de Desenvolvimento Proximal provê psicólogos e educadores de um instrumento através do qual se pode entender o curso interno do desenvolvimento. Usando esse método podemos dar conta não somente dos ciclos e processos de maturação que já foram completados, como também daqueles processos que estão em estado de formação, ou seja, que estão apenas começando a amadurecer e a se desenvolver.

De acordo com Vigotski (2007), a Zona de Desenvolvimento Proximal caracteriza o desenvolvimento mental de maneira prospectiva. Essa abordagem é interessante quando pensamos o desenvolvimento em sua possibilidade de vir a ser, ou seja, aquilo que a criança pode aprender em interação com os outros e com os símbolos e instrumentos desenvolvidos pela cultura.

De acordo com Fino (2001, p. 6):

A ZDP fornece aos psicólogos e educadores uma ferramenta através da qual pode ser compreendido o curso interno do desenvolvimento, e que o uso desse método pode permitir a tomada em consideração dos ciclos e processos de maturação que já estão completos, além dos que estão em estado de formação.

Com base no conhecimento desta teoria e de seus principais conceitos, tais como, o de Zona de Desenvolvimento Proximal, entende-se que o professor em sua prática pedagógica 
pode fazer uso do dever de casa como um mecanismo para a promoção da aprendizagem. Isso implica pensar que as atividades extraclasses podem ser elaboradas no sentido de ampliar a percepção da turma sobre o que já foi discutido na aula, trazer desafios, provocar indagações, favorecer o desenvolvimento da motivação intrínseca e, sobretudo, estimular o constante espírito científico da pesquisa.

É interessante mencionar aqui a relevância do conhecimento por parte dos educadores sobre o processo de desenvolvimento humano, considerando que este direciona os caminhos possíveis que os indivíduos devem percorrer em seu processo de amadurecimento, bem como aponta as funções psicológicas que já foram amadurecidas.

Ainda sobre isso, Vigotski (2007, p. 97) destaca:

A distância entre o nível de desenvolvimento real, que se costuma determinar através da solução independente de problemas, e o nível de desenvolvimento potencial, determinado através da solução de problemas sob a orientação de um adulto ou em colaboração com companheiros mais capazes.

Essa posição de Vigotski (2007) deixa clara a importância do papel do professor e de outros sujeitos sociais no processo de desenvolvimento humano, bem como aponta para a qualidade das interações propostas nos espaços escolares.

Nessa perspectiva, em que se pressupõe que a aprendizagem se adianta ao desenvolvimento, podemos pensar, então, na relação entre as aulas que acontecem nas escolas, as atividades nela realizadas e aquelas que são determinadas para a criança executar em casa. O que se observa nas práticas escolares cotidianas é o cumprimento regulado de uma agenda da qual as crianças e suas famílias não podem fugir. Para Carvalho (2006), a legitimação do dever de casa como uma política formal tem graves implicações para um projeto de equidade da educação escolar.

Partindo da constatação que o uso do dever de casa é uma realidade constante das escolas brasileiras, faz-se necessário pensar sobre o sentido e o significado dessa política. Mitjáns Martínez e Rey (2017) defendem que o processo educativo é complexo e tem diferentes dimensões e reduzi-lo à sua dimensão psicológica, conteudista, implicaria uma psicologização da educação.

Para a maioria dos pais, o dever de casa compreende a ocupação do outro turno no qual a criança não está na escola, mas continua realizando atividades orientadas por ela. No entanto, para as crianças, muitas vezes, esse excesso de atividades compromete seus momentos de lazer e criação artística. Partindo da premissa que os pais compreendem o dever 
de casa como uma obrigação escolar e até como um parâmetro para avaliar a qualidade da escola, é importante refletir sobre a dimensão psicológica dessa estratégia no campo da educação.

Para compreender o sentido e o significado que o dever de casa adquire no processo educacional, bem como seus usos na relação família-escola, faz-se necessário esclarecer esses conceitos à luz da teoria histórico-cultural. Aguiar (2015) pontua que Vigotski faz uma distinção entre um e outro e "evidencia a dialética da constituição da consciência, a integração entre afetivo e cognitivo, o caráter social, histórico e único do sujeito" (AGUIAR, 2015, p. 129).

Aguiar (2015, p. 129), menciona - que para Vigotski:

Significado é uma construção social, de origem convencional, relativamente estável. O homem, ao nascer, encontra um sistema de significações, pronto, elaborado historicamente. Por outro lado, o sentido, é a soma dos eventos psicológicos que a palavra evoca na consciência. O sentido se constitui, portanto, a partir do confronto entre as significações sociais vigentes e a vivência pessoal.

Oliveira (2009), também com base na teoria de Vigotski (2007), explica que o significado se refere ao sistema de relações objetivas que se forma ao longo da história e que é partilhado por todas as pessoas e o sentido é o significado afetivo das vivências para cada indivíduo. A partir dessa perspectiva, podemos compreender o dever de casa como uma política de significado amplo, governamental, regulatório, já o seu sentido, é apenas percebido de forma diferente por cada criança no interior de suas famílias.

Carvalho (2006, p. 88, grifos da autora), explica:

Como o principal veículo de interação família-escola, é mais do que uma prática cultural ou uma política informal desenvolvida por famílias e escolas e seus agentes (pais/mães e professoras/es): constitui de fato uma política formal (mais ou menos regulamentada) que articula os esforços educativos destas instituições, portanto através dele a família (e seu acompanhamento ou omissão, do ponto de vista da escola) se torna objeto de política educacional. Por um lado, como trabalho escolar transferido para casa, o dever de casa pode consistir numa estratégia defensiva contra a cobrança da responsabilidade estatal de prover educação formal suficiente, quantitativa e qualitativamente. Por outro lado, pode consistir numa estratégia de regulação da vida privada pela política pública, através da instrução ou disciplinamento da família pela escola.

Ligado à vida familiar, o dever de casa ao longo do tempo vem ganhando conotações diferentes. Quanto ao seu sentido, percebe-se que as famílias mais abastadas, que dispõem de mais recursos para viabilizar as exigências das escolas, o percebem como uma espécie de 
reforço, que garante melhor desempenho nas matérias escolares. Em contrapartida, famílias desassistidas economicamente, apresentam maiores dificuldades para operacionalizar a realização de atividades em excesso. "Da perspectiva da família, o dever de casa pode ser uma necessidade legítima e uma prática desejável, ou um fardo e uma imposição, dependendo de condições materiais e simbólicas variáveis, recaindo particularmente sobre as mães" (CARVALHO, 2006, p. 88-89).

\section{Considerações finais}

Este texto propôs levantar uma reflexão sobre os modos de uso do dever de casa pelas escolas e no contexto das famílias. A análise aqui empreendida não pretendeu condenar ou defender essa prática, que já faz parte da cultura escolar ocidental, contudo, suscita reflexões sobre os significados e sentidos que estão implicados nessa política educacional e busca fomentar novos/outros estudos e pesquisas que envolvam os saberes psicológicos.

A revisão da literatura indicou que, em sociedades capitalistas, o uso rotineiro do dever de casa e sua quantidade implica mudanças nas relações familiares. Logo, crianças oriundas de famílias mais abastadas contam com mais recursos tecnológicos e pessoais para realizar suas tarefas. "Isso objetivamente coloca as diferentes famílias em posições desiguais diante do mercado escolar, já que elas não dispõem de condições materiais e culturais idênticas para fazer face a esse papel” (RESENDE, 2012, p. 163).

A ampliação dessa prática revela um cenário que se mostrou bastante propício ao surgimento de franquias educacionais especializadas em reforços escolares e que atendem uma parcela da sociedade que dispõe de mais recursos financeiros. Soares (2011) acredita que existe uma "interferência fundamental da origem econômico-cultural das famílias no sucesso escolar dos filhos, apontando o acompanhamento das tarefas escolares e supervisão dos estudos pelos pais como itens geradores desse êxito" (SOARES, 2011, p. 43).

O levantamento dos textos e pesquisas sobre o dever de casa, indicam também que existe uma legitimidade de todo sistema educacional quanto ao seu uso, muito embora, boa parte das famílias o utilizem como um indicador de qualidade da escola. Marinho-Araújo e Oliveira (2010) apontam que o acompanhamento dessas tarefas pelas famílias tende a reduzir bastante com o início da adolescência.

Nesse contexto social, brevemente esboçado pela literatura, podemos pensar a criança na perspectiva sugerida por Filho (2012), como uma "mini-executiva", que vai à escola um turno e no outro frequenta, aulas de inglês, matemática e demais reforços e as famílias, na 
justificativa de falta de tempo, terceirizam suas responsabilidades. Inserida nessa rotina adultocêntrica, é lógico que não sobra tempo para a criança brincar, experimentar, inventar, o que compromete sua capacidade de criatividade e imaginação, processos estes de grande importância na formação do desenvolvimento psíquico.

No âmbito da teoria histórico-cultural em Psicologia, Mitjáns Martinez e Rey (2017) reforçam a importância do conceito de Zona de Desenvolvimento Proximal como diferença/distância entre o que a criança pode fazer sozinha, Zona de Desenvolvimento Real, ou com a ajuda de um mais experiente. Partindo da ideia defendida nesse texto, a qual sustenta que o dever de casa pode colaborar para o desenvolvimento de processos psicológicos superiores, considerando de forma coerente a Zona de Desenvolvimento Proximal da criança, compreendemos que o uso sensato dessa política pode ser um grande aliado no processo educacional.

Por fim, concluímos que o dever de casa é uma estratégia que potencializa a aprendizagem e que pode e deve ser utilizada desde o início da escolarização da criança contudo, também deve ser considerado que fatores como motivação intrínseca e impactos emocionais interferem na aprendizagem. Logo, pressupõe-se que não basta o dever de casa dialogar apenas com a Zona de Desenvolvimento Proximal da criança, é necessário pensar o seu significado enquanto política formal na perspectiva do currículo e da forma pela qual ele é trabalhado nas escolas, bem como sobre o sentido da sua realização para os estudantes e suas famílias.

\section{REFERÊNCIAS}

AGUIAR, W. M. J. Consciência e atividade: categorias fundamentais da Psicologia Sóciohistórica. In: BOOK, A. M. B.; GONÇALVES, M. G. M.; FURTADO, O. (Orgs). Psicologia Sócio-histórica: Uma perspectiva crítica em psicologia. São Paulo: Cortez, p. 117-135. 2015

CARNEIRO, B. V. Dever de casa algumas reflexões. Revista Educação, vol. 2, Jundiaí, p.34-45. São Paulo, 2010.

CARVALHO, M. E. P. Escola como extensão da família ou família como extensão da escola? O dever de casa e as relações família-escola. Revista Brasileira de Educação, n.25, 94-104, 2004.

CARVALHO, M. E. P. O dever de casa como política educacional e objecto de pesquisa.

Revista Lusófona de Educação, 2006, n. 8, 85-102, Lisboa, Portugal, 2006.

CARVALHO, M. E. P.; BURITY, M. H. Dever de casa: visões de mães e professora. XXVIII Reunião anual da ANPEd, Caxambu, MG, 2005. 
FILHO, M. J. Acriança terceirizada: Os descaminhos das relações familiares no mundo contemporâneo 6 ed. Campinas, São Paulo, 2012.

FINO, N. C. Vygotsky e a Zona de Desenvolvimento Proximal (ZDP): Três implicações pedagógicas. Revista Portuguesa de Educação, vol. 14, n. 2, 2001, p. 1-13. Universidade do Minho. Braga, Portugal.

GONZÁLEZ REY, F., MITJÁNS MARTÍNEZ, A. Psicologia educação e aprendizagem escolar: avançando na contribuição da leitura cultural histórica. São Paulo: Cortez, 2017.

MARQUES, R. A escola e os pais, como colaborar? Lisboa: Texto Editora, 1999.

OLIVEIRA, C. B. E.; MARINHO-ARAÚJO, C. M. Relação família-escola: intersecções e desafios. In: Estudos de Psicologia, vol. I 99-108, Campinas, São Paulo, 2010.

OLIVEIRA, M. K. Vigotsky: aprendizado e desenvolvimento: um processo sócio-histórico. São Paulo: Scipione, 2009.

REGO, T. C. Vigotsky: Uma perspectiva histórico-cultural da educação. 25 ed. Petrópolis, Rio de Janeiro. Editora Vozes, 2014.

RESENDE, T. F. Dever de casa: questões em torno de um consenso. XXIX Reunião Anual da Anped, GT 14, Caxambu/MG, out. 2006.

RESENDE, T. F. Entre escolas e famílias: revelações dos deveres de casa. Paidéia, v. 18, n. 40, 385-398, Ribeirão Preto, 2008.

RESENDE, T. F. Dever de casa, espelho de desigualdades educacionais e sociais. Educação em Revista, Belo Horizonte, v. 28, n. 03, p. 159-184, set. 2012.

RESENDE, T. F.; CANAAN, M. G.; REIS, L. S.; OLIVEIRA, R. A.; SOUZA, T. C. S. Dever de casa e relação com as famílias na escola de tempo integral. Educação \& Realidade, v. 43, n. 2, p. 435-456, abr./jun. Porto Alegre, 2018.

SOARES, E. R. M. O dever de casa no contexto da avaliação das aprendizagens.

(Dissertação de Mestrado), Faculdade de Educação, UNB, Brasília, Distrito Federal, 2011.

SUEHIRO, A. C. B.; BORUCHOVITCH, E. Motivação para Leitura e Lição de Casa no Ensino Fundamental. Psicologia: Teoria e Pesquisa, v.35 p.1-11, São Paulo, 2019.

VIGOTSKY, L. S. A formação social da mente. 7. ed. São Paulo: Martins Fontes, 2007.

VIGOTSKY, L. S. Pensamento e Linguagem. 4. ed. São Paulo: Martins Fontes, 2008. 


\section{Como referenciar este artigo}

SILVA SOUZA, A. da. O dever de casa e sua relação com a zona de desenvolvimento proximal. Doxa: Rev. Bras. Psico. E Educ., Araraquara, v. 22, n. 00, p. e021008, 2021. eISSN: 2594-8385. DOI: https://doi.org/10.30715/doxa.v22i00.15063

Submetido em: 27/04/2021

Revisões requeridas em: $15 / 05 / 2021$

Aprovado em: 20/06/2021

Publicado em: 25/06/2021 